\title{
COVID-19 Impact on Online Purchasing Behaviour in Oman and the Future of Online Groceries
}

\author{
Abdul Rahman Rashid Saleh AL-Hawari, Adela P. Balasa, and Zouhaier Slimi
}

\section{ABSTRACT}

This paper studies the impact of COVID-19 on customers purchasing behaviour and predicts the future of logistics movements in online groceries in Oman. The paper aims to study the impact of COVID-19 on electronic groceries and E-Shoppers purchasing behaviour and investigate the future of online groceries. The research used an online qualitative survey that targeted the grocery consumers in Oman, including citizens and residents, to evaluate their purchasing behaviour and satisfaction with online grocery shopping in Oman. The survey was reinforced by interviews to analyze the future of logistics movements in online groceries in Oman by interviewing two CEOs of local electronic groceries, one logistics services providing company and three consumers. The results revealed that the COVID-19 pandemic contributed to a change in consumer behaviour where it encouraged many people to shift their grocery shopping lifestyle from traditional to online. However, the future of electronic grocery logistics movements in Oman is still not precise due to the current situations of the covid-19 and the lifestyle of Omani citizens. Though, the future of electronic groceries in Oman has a great future, especially with the increase of Oman's online shopping users due to the Covid-19. Findings revealed that COVID19 had changed customers' purchasing behaviour. The participants suggested that Omani electronic groceries improve the efficacy of their services to attract more customers. They also recommended providing and adding various products that customers may require in all Omani cities rather than only limited cities.

Keywords: COVID-19, E-commerce, Electronic groceries, Purchasing behaviour, Logistics.
Submitted: June 14, 2021

Published: July 06, 2021

ISSN: $2507-1076$

DOI: $10.24018 /$ ejbmr.2021.6.4.923

Abdul Rahman Rashid Saleh AlHawari

B.A student the Logistics and Transport Management department, International Maritime College Oman, Sohar, Oman.

(e-mail: 003801-16@imco.edu.om) Dr. Adela P. Balasa Author

Assistant Professor -Economic Science, Logistics Management, International Maritime College Oman, Sohar, Oman.

(e-mail: adela@imco.edu.om)

Zouhaier Slimi*

Lecturer Foundation Department, International Maritime College Oman, Sohar, Oman

(e-mail: slimizou @hotmail.com)

*Corresponding Author

\section{INTRODUCTION}

Online shopping has become trendier, especially during Covid-19 and the fourth industrial revolution. Therefore, it is essential to be up to date with technology such as online shopping from e-groceries. E-commerce of grocery products is related to using electronic networks as a distribution channel. It targets individuals, described as a smooth and modern relation between business-to-consumer (B2C) [1]. Online shopping has become more popular because of the COVID-19 pandemic, and consumers' e-purchasing behaviour towards groceries has increased.

On the other hand, the consumer's demand for online shopping has increased because it provides customers with access to a massive variety of items and products from their homes, with a high level of convenience, safety, and door-todoor delivery services [2]. Also, online groceries offer better value to consumers than the traditional supermarket at almost the same cost level. Furthermore, the pandemic encouraged many businesses and companies to shift their classics to online services, which facilitated online shopping for customers and made shopping safer, comfortable, and flexible [3]. So, it increased people's safety by delivering their items to their homes and reducing their time shopping.

\section{A. Background of the Research}

The research topic is on COVID-19 impact on e-groceries and purchasing behaviour and the logistics of future online groceries.

Due to COVID-19, e-commerce has accelerated to include new firms, a massive number of customers, and new types of business, including online groceries [3].

Globalization has changed the shopping environment over the last decades through two main drivers: technology developments and an expanding global business [4] Although the advantages of online shopping for grocery products due to the smooth use of internet networks and the development of technologies, online grocery product purchasing still has many challenges and low competition compared to other products.

Due to the rapid development of technology, many online shopping users are making it highly in demand, especially during the COVID-19 pandemic. However, in Oman, online grocery shopping is still lagging due to the lack of awareness of its positive side. 


\section{B. Statement of the Problem}

COVID-19 has changed consumers' E-purchasing behaviour for groceries and food in Oman for safety reasons and confinement regulations. However, there are problems with the reliability of customer orders and last-mile delivery on the logistical services where customers face issues to receive their orders. As an example, one customer argued that he paid a delivery fee. However, he did not receive his items. After he contacts the call centre, they told him that he must collect his articles from the LuLu hypermarket store. According to consumers, other problems are data-driven decisions and predictive analysis, reverse logistics in online grocery, and product quality. This paper also investigates the challenges and their effects on online groceries, customer purchasing behaviours, the future of online shopping, and how to overcome these challenges.

\section{Research Questions}

1. What are the impacts of COVID-19 on consumers' behaviour and online shopping in Oman?

2. What is the future of online shopping in Oman?

\section{Research Objectives}

1. To study the impacts of COVID-19 on consumers' behaviour and online shopping in Oman?

2. To predict the future of online shopping in Oman.

\section{E. Research Justification}

Due to the new worldwide trends caused by the COVID19 and the adaptation of technological advancements on Ecommerce, the COVID-19 pandemic has changed the way of shopping from the traditional way to online. The latter includes grocery products, where consumers' e-purchasing behaviour towards groceries and food has been increased worldwide and even in Oman. Globally, $49 \%$ of consumers during the pandemic shifted their shopping behaviour from traditional to online, more now than they did before the COVID-19 [5]. In addition, 79\% of consumers worldwide have bought their grocery needs online in the grocery shopping field, with an increase of $19 \%$ compared with a year ago [5]. These purchasing behaviour changes act as an essential factor in calculating the future logistics movement in Oman's E-groceries sector. Therefore, the overall development needs to effectively analyze the requirements and challenges and then take actions as per the requirement to reduce and overcome the obstacles of electronic grocery shopping and facilitate logistics movements in online groceries.

\section{F. Research Significant}

The researchers believed that this study is critical because it is a shift to suit consumers to meet their needs safely and conveniently and prevent both parties (the seller and the buyers) from the risks brought by the pandemic. The epurchasing behaviour of consumers towards groceries, food has been increased. The technology is developing faster, and it is essential to walk along with the technology to make the market competitive enough. The analysis helps in creating effective strategies to overcome the challenges in Oman.

\section{G. Scope of Research}

This research focuses on electronic groceries and purchasing behaviour by analyzing the future of logistics movements in online groceries. This study evaluates the impact of Covid-19 on online purchasing behaviour, the high level of convenience and safety that electronic groceries provided to the users through the added value services like door-to-door delivery services, and the logistics challenges that may affect customer's satisfaction.

The study areas for this research are Sohar, Muscat, and Salalah, where most online groceries provide their services in those cities, as shown in Figure 1.

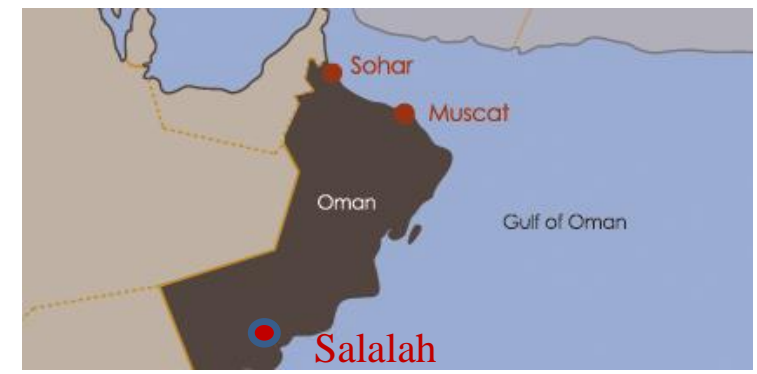

Fig. 1. Muscat, Sohar, and Salalah location in Sultanate of Oman map [6]

\section{H. Limitation of the Research}

There are some limitations, where the overall conclusion will be based on the thinking and ideas of the few online grocery shopping users, owners, and sales department managers. Therefore, further interviews should be made collecting all the employees working in the targeted online groceries that provide online shopping services. In addition, the study should be made on all the E-groceries markets in Oman to make the appropriate conclusions of the study. There are also some limitations related to online groceries' cooperation and the possibility of sharing the customer's purchasing orders' data to complete the study research.

\section{LITERATURE REVIEW}

E-commerce of grocery products is related to using electronic networks as a distribution channel [1]. Consumers make various decisions regarding selecting a shopping place or network, financial matters and choosing the product brand while buying any product in online shopping. The customers' demands change as per their needs or desire for the consequences [7]. Over the last decades, the development and increase in online shopping have provided a terrific, impressive chance to the shippers to build the benefit and reduce the cargo spend [8]. Due to the COVID-19 pandemic, e-commerce has accelerated to include new firms, a massive number of customers, and new types of products [9]. The demand for online groceries has increased because it provided customers with access to a significant variety of products from their homes, with a high level of convenience and safety, and door-to-door delivery services [3].

\section{A. The COVID-19 Pandemic \& Online Grocery Shopping}

The COVID-19 pandemic has contributed to the expansion of e-commerce has accelerated to include new firms, a massive number of customers, and new types of products [9]. Lately, the use of online groceries to buy products has registered an enormous increase in some countries due to the 
covid-19 pandemic [10]. From 2014-2019, online grocery shopping has experienced continuous growth worldwide by $21 \%$ per year [9]. Due to the COVID-19 pandemic and the lockdown in most countries, the popularity and the demand for online groceries have increased because it provided customers with access to a significant variety of products from their homes, with a high level of convenience and safety, and door-to-door delivery services [11]. In Germany, the online sales of grocery products have grown significantly, as well as Korea, wherein the second, the e-commerce transaction value has increased by $15.8 \%$ between the period from July 2019 and July 2020, where it observed a growth by $48 \%$ for household goods, and $46.7 \%$ for food and beverages that provided by the online groceries [12].

Furthermore, In China, online grocery shopping for food products has a massive growth, with an increase in sales by $36 \%$ from January to April 2020, compared with the same period in the previous year [13]. In addition, a global consumer survey has been conducted, where it measured the digital shopping for grocery products. The survey shows that the new users of online grocery shopping have increased over $50 \%$ during the COVID-19 pandemic, where most of them are from Brazil and South Africa [12]). Moreover, In the US, $21 \%$ of adults report having ordered their groceries products online during the COVID-19 pandemic, comparing with 19\% among the elderly (age 65+) [14]. So, the COVID-19 pandemic contributed to a change in consumer behaviour where it encouraged many people to shift their grocery shopping lifestyle from traditional to online.

\section{B. Customer Behaviour and Last Mile}

Home deliveries of online grocery products are considered essential for e-shopping [15]. The last mile is described as the final stage in the distribution process of online retailing, and it is considered one of the most challenging elements of the supply chain of e-grocery shopping [16]. The sustainability of the last mile delivery of online groceries depends on two significant factors: to what extent home delivery of online groceries substitutes personal travel to the hypermarket or grocery stores, and how far it more efficient in terms of energy, efforts, the accuracy of delivery time [17]. In addition, many researchers have looked at the influence of consumer behaviour in online groceries. For example, Reibstein [18] found that it is heterogeneous from customers in online groceries sales, where a product's price plays an essential role in the purchasing behaviours.

On the other hand, Hsiao and Zhang [19] found that the delivery time is critical in the transaction process of online groceries, where the delivery times play a significant role in e-groceries logistics, which can directly be affecting on customers' behaviour and preferences [16]. Boyer and Hult [19] showed that the delay in the deliveries results in customer dissatisfaction, where they conducted case studies in an online grocery industry to survey customers' purchasing behaviour. They found that three main elements significantly impact customers' buying intentions from online groceries: service quality, credibility and smooth communication, assortment and product quality, and the smooth use of the online grocery application [20]. They also found that convenience in receiving the order at the accurate time and the fast delivery is more important than the product's actual price [20]. Schnedlitz stated that online grocery shopping users prefer home delivery (door-to-door delivery) instead of alternative delivery solutions like a collection delivery point [21]. Blauwens [19] stated that the logistics services in the last mile delivery play a significant role and an excellent opportunity to induce and attract customers. The scheduled time slots for delivery can improve the customer service and efficiency of the delivery [22]. In conclusion, the logistics services of online groceries play an essential on customer purchasing behaviour and their loyalty [20].

\section{Impact of Technology on E-groceries Logistics.}

Globalization and technology development have impacted trade's positive internationalization [23]. It has forced many people to shift their grocery shopping behaviour from the traditional way to be online. So, it led to pressure on the retail to improve their service quality and increased competitive advantages through better customer relationship management by using consumer databases [23]. These databases will help serve customers better, expect their next orders (predictive analytics suggested based on their previous orders), and reduce the time customers spend buying their groceries due to digitalization [24]. Data mining is also an advantage from the databases, where it supports the online groceries to provide solutions and actionable patterns for decision support [25].

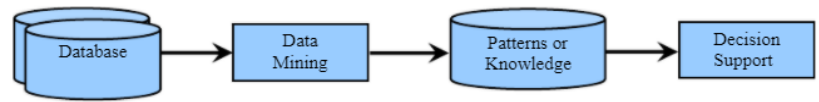

Fig. 2. Data-Driven Decision Support [25] (P:465).

Today, the new technologies facilitate the logistics operation of e-groceries, where the RFID system allows customers to track their shipments from the store until they get them [26].

Yang. S, Song. Y, Tong. S [27]found that the logistics sector's significant change in consumer habits [27]. Consumer habits have become a part of the increased expansion in online business or shopping. There is a massive transformation in logistics due to the shift from physical retail shopping to online shopping [27]. The other impact or change is the warehouse. Earlier warehouses were used only by retailers and manufacturers, but warehouses fit into the retail supply chain [28]. Increased use of technology has also increased the customers' expectations regarding the speedy delivery of the products. Like automation and robotics, the branch of technology also significantly impacts a speed delivery's demands [28]. Some of the top trends or the future of logistic movements in online grocery shopping that helps online groceries in creating the competitive advantage are:

Automation and digitalization help the shipper wind up or dissolve the accurate web-based business coordination and power shippers to move more items at a low cost [29]. Mobile technology and GPS innovations have increased the value of existing production networks following the system [29]. Using innovative delivery methods or strategies will help online groceries quickly deliver more items. More significant market shares through SaaS platforms (Software as a service) enhances coordination's productivity. It fulfils more requests as shippers move forward to open better ways to make everything remain focused and fair [30]. Overall, the 
technology will facilitate the customer experience in online grocery shopping and help smooth operation, communication, and financial flow.

\section{The logistics \& Other Challenges of Online Groceries}

Many researchers have discovered the challenges faced by electronic groceries and e-retailers. Those challenges include data-driven decisions and predictive analysis. As the new age, digital customers are astute and informed, making supply chain management more influenced by their needs and actions [25]. Last-mile delivery is another challenge, where it is and remains a significant challenge for logistics. There is the chance that customer satisfaction gets affected due to the traffic and order density, which may take more time for the delivery process [31].

Furthermore, moving towards a more customer-centric market is considered a challenge, where the industry of ecommerce is more consumer-centric, and the focus has shifted towards profitability [32]. The company sees logistics as a thing that makes it possible to drive customer satisfaction and realizes that delivering the goods is an unusual customer experience that creates a competitive advantage. Most customers are expecting to receive their items on time [32]. Also, delivery services and product quality are other of the most complicated challenges. It is difficult to convince customers that the products they will receive from the online groceries are of the same quality as what they select in the Shop. Customers have a severe concern when buying some kinds of products via online groceries, such as meats, fruits, vegetables, and other fresh items [33]. Finally, the trade-off between customer demand on a product versus the organization's ability to accurately predict that product and keep it available in their stock is challenging [34]. When the consumer buys by themselves from the grocery, if he did not find their needed product on the shelves, such as milk from Mazoon Dairy Company, they will unconsciously choose the same product: the milk from another company like Almarai. However, consumers shopping over online groceries give up control of this decision, and often they become uncomfortable with the shop's substitution choices [34].

\section{E. Literature Gaps}

The number of sources related to the logistics movement in online grocery shopping is limited. Also, studies related to the future of logistics movement in online groceries are almost non-existent. Furthermore, researchers did not focus intensely on the impact of this industry on the logistics movement. There is also no clear view of the future of logistics movement in online grocery shopping due to unstable consumers' behaviours and satisfaction. Also, the trend of the online groceries' future could be shrinking after the COVID-19 pandemic. In the following chapters, the researcher will study global trends such as COVID-19 in electronic groceries and how it affects customer purchasing behaviours. The researcher also will analyze the future of the logistics movement in online grocery shopping in Oman.

\section{ReSEARCh Methodology AND DAta Collection}

A. Research Framework

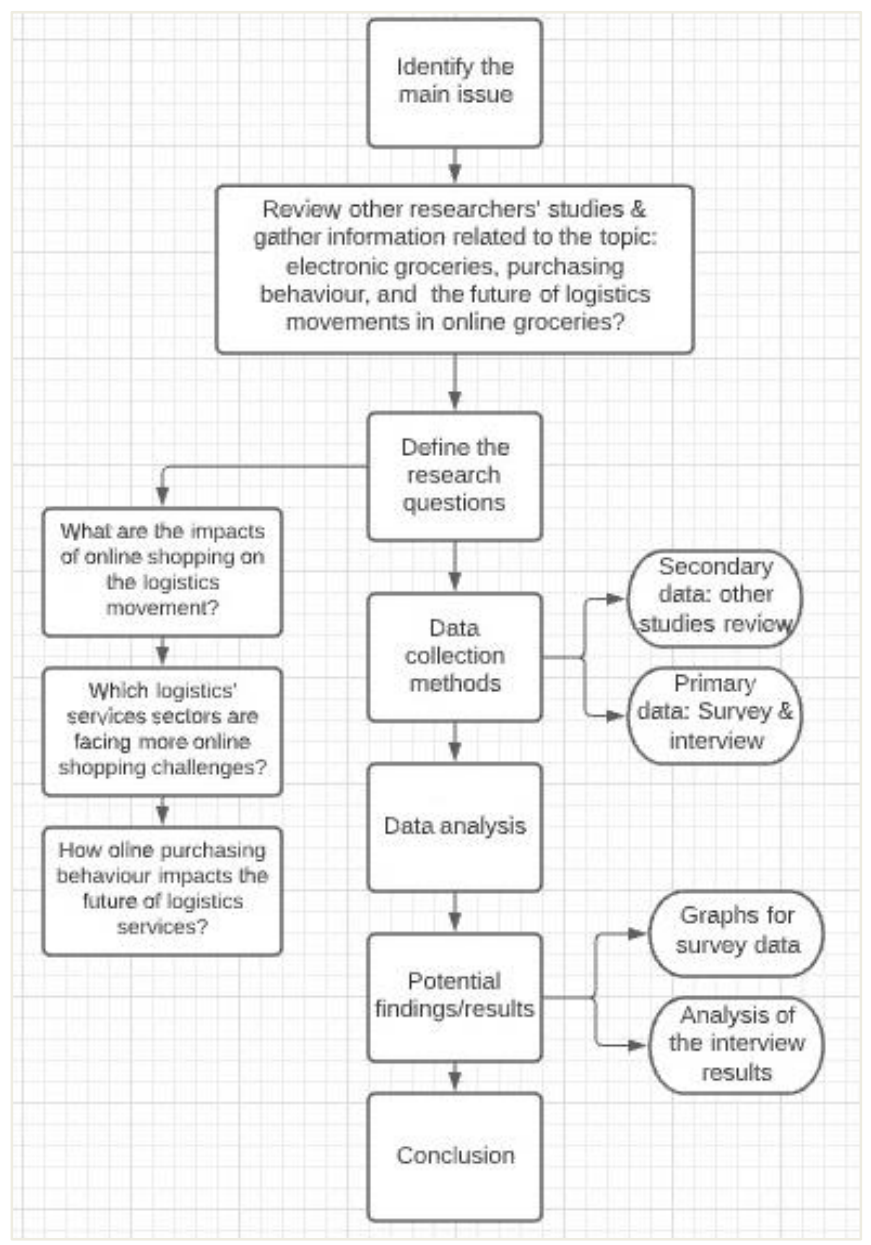

Fig. 3. Research Framework.

\section{B. Data Collection}

This paper uses the quantitative approach as it helps in investigating and answering the research questions effectively. Moreover, this method supports in data collection and analyzing process [35]. Primary data was collected via a qualitative survey and interviews, while the secondary data via relevant academic sources.

Both the survey and interviews were conducted via social media channels, including WhatsApp and email.

Fig. 4 shows participants' gender. The researcher collected 208 responses, where 114 participants are male, and they form $54.8 \%$ of the survey, and 94 participants are female, and they form $45.2 \%$ of the survey.

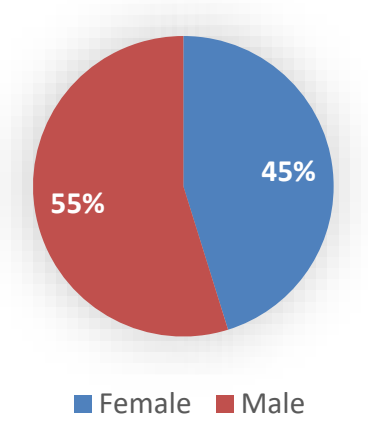

Fig. 4. Gender 
Fig. 5 is showing the age level of the participants who participate in the survey answer. 123 of participants' ages range between (18-25), and they form $59.1 \%$ of the participants. 55 of participants' ages range between (26-30), and they constitute $26.4 \%$ of the participants. 23 participants' ages range between (31-40), and they form $11.1 \%$ of the participants. 6 of the participants' ages range between (4150 ), and they comprise $2.9 \%$ of the participants, 1 participant his age range (65 or more), and forms $0.5 \%$ of the participants.

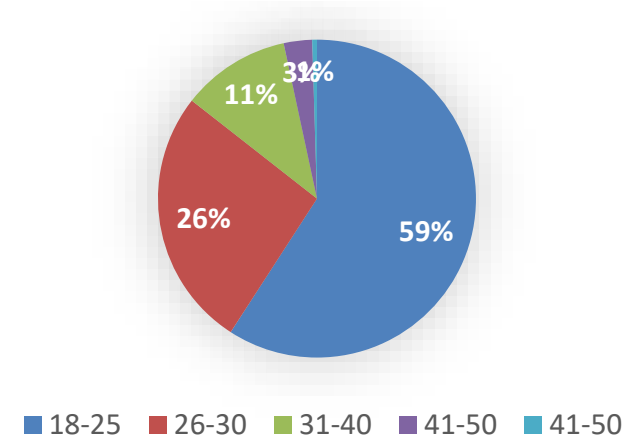

Fig. 5. Participants age level.

Fig. 6 is showing the current occupation of the participants. 80 of the participants are students, and they form $38.5 \%$ of the participants. 65 of the participants are employed, and they include $31.2 \%$ of the participants. 55 of the participants are unemployed, and they form $26.4 \%$ of the participants, and 8 of the participants are other, where they may be entrepreneurs or retirees, and they form $3.8 \%$ of the participants.

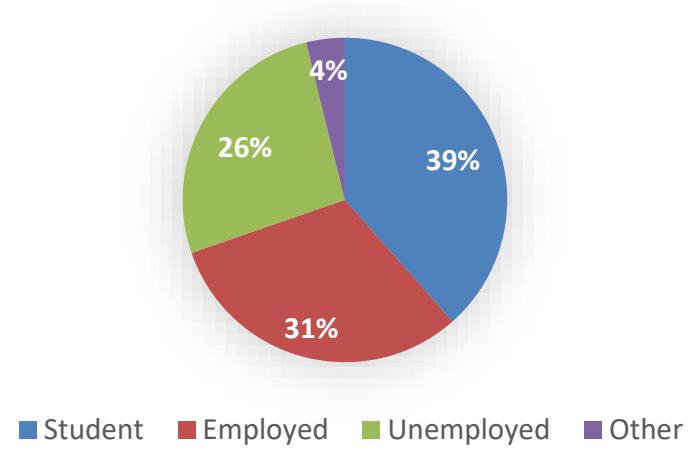

Fig. 6. Participants current occupation.

\section{Sampling Technique and Potential Respondents}

The survey was distributed to consumers to evaluate their purchasing behaviour and satisfaction with online grocery shopping in Oman. The received survey responses were 208 responses. The questionnaire was designed in such a way that it helped to get effective results to draw the proper conclusion of the comprehensive research study related to customer satisfaction on Omani e-groceries services. The interviews targeted CEOs of online grocery shopping providers in Oman, where the researcher got responses from The CEO of Geeb application, Ayshay application, owner of logistics services company, Tawseel plus company, and three consumers. The aim is to collect the primary data for the research study and have a practical evaluation and analysis of the result of the purchasing data for this empirical study.

\section{Data Analysis}

For both the survey and interviews, the researcher will divide the data analysis approaches into three main parts. These parts will study the impacts of online shopping on logistics movement, figure out the sectors of the logistical services facing more online shopping challenges, and evaluate customers' purchasing behaviours and satisfaction with online grocery shopping in Oman. The questionnaire will be designed in such a way that it helped to get the effective results to draw the fitting conclusion of the comprehensive research study related to customer satisfaction on Omani e-groceries services and the future of logistics movements in online groceries. The main objective of the research is to analyze the future of logistics movements in online groceries based on consumers purchasing behaviours, and the impact of global trends, like the COVID19 pandemic, on consumers buying behaviour of grocery products.

\section{FINDINGS AND DISCUSSIONS}

\section{A. Findings}

The researcher has used both surveys and interviews to gain information and data from CEOs of Omani electronic groceries, a logistics services provider, and consumers. This survey and interviews will help the researcher analyze the future of electronic groceries in Oman through current customers' purchasing behaviours.

The interview was held with chief executive officers of two electronic groceries, a CEO of the Geeb application; CEO of Ayshay application; and one a chief executive officers of a logistics services provider, CEO of Tawseel Plus Company, and three consumers.

Figure 7 is showing the Nationality of the participants. 196 of the participants are Omanis, and they form $95.1 \%$ of the participants, and 10 of the participants are non-Omani, and they form $4.9 \%$ of the participants.

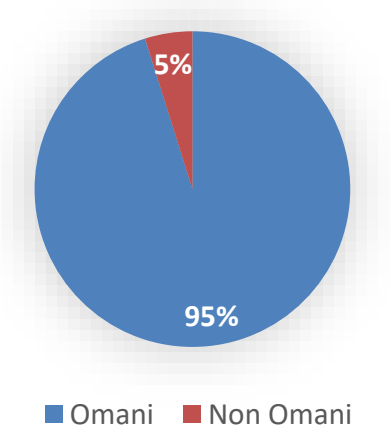

Fig. 7. Participant's nationality.

\section{1) Shopping behaviours}

Fig. 8 shows the shopping behaviours of consumers and where they prefer to have their grocery shopping. There are 111 respondents, and they form most participants, are buying their grocery products from supermarkets, and form $53.4 \%$ of the participants. Besides, 73 participants buy their grocery products from a Local Corner Shop, and they constitute $35.1 \%$ of the participants. In contrast, 24 participants buy 
their grocery products from the electronic groceries "online," and they form $11.5 \%$ of the participants.

The low number of people who prefer to use electronic grocery shopping in Oman is because they do not offer attractive offers that may encourage society to use electronic shopping to buy their grocery needs. Also, the lack of customer awareness of the advantages of electronic shopping is another reason. The marketing of electronic groceries in Oman is not fair enough to reach many citizens and force them to use e-shopping. Hanaa Al Mayahi (consumer) stated that the low number of electronic grocery users in Oman is because of the disadvantaged background of electronic groceries in Oman. She said that there are several delays in the delivery of the products. Also, some electronic groceries bring some products, such as milk products, with a very close expiration date, the fruits and vegetables are not fresh, and sometimes the packing is awful.

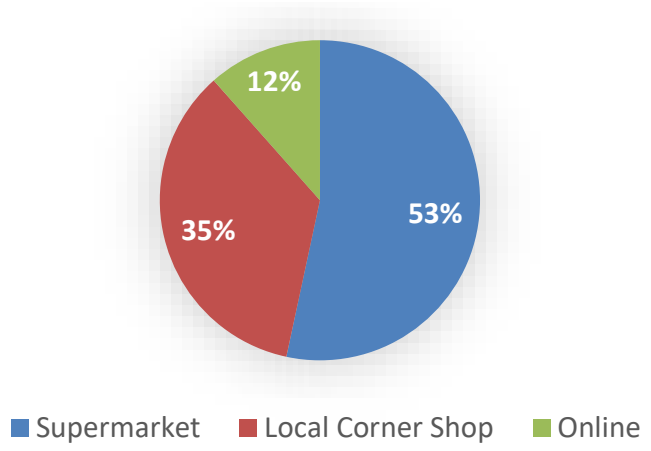

Fig. 8. Where participants prefer to have their grocery shopping.

Furthermore, after-sales service is fragile because we as customers can sometimes not return or exchange the items. They also do not show the expiration date, which is necessary for some products like milk products. Besides, when I used one of the applications that provide online shopping for grocery products, the application's language was only in English, were that not good because we are Arabic people, and not all customers can understand the English language. Sami Awladwadair (Consumer) said that there are limited options of items list available in the local electronic groceries, where sometimes he may be forced to visit a local grocery and physically collect his needs since it is not available in the online groceries. Also, electronic groceries services are available only in the main cities in Oman, like Muscat, Sohar and Salalah.

Fig. 9 shows how often participants buy groceries per month. 86 participants get their grocery products 1-2 times a month, and they form $41.3 \%$ of the participants. On the other hand, 72 participants are buying their grocery products 3-5 times a month. They constitute $34.6 \%$ of the participants, and 50 participants buy their grocery products 5 times or more a month. They form $24 \%$ of the participants.

Fig. 10 shows if participants currently do their grocery shopping online. Again, most participants are answered "No," where they currently do not do their grocery shopping online, where their number was 151 participants, and they form $72.5 \%$ of the participants. On the other hand, 57 participants are currently buying their grocery products online, including $27.4 \%$.

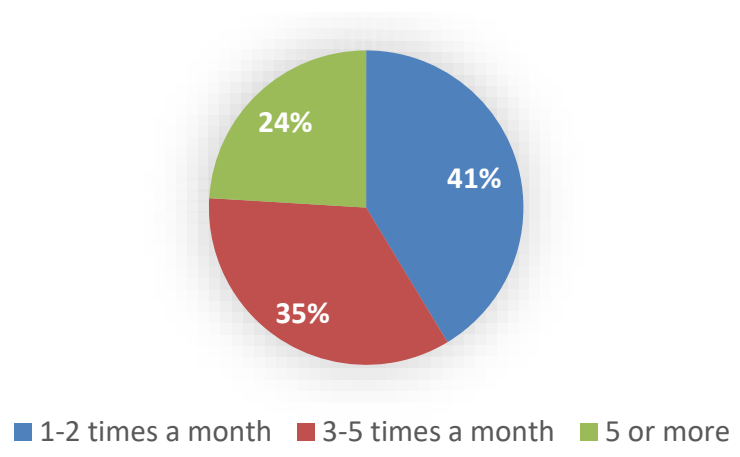

Fig. 9. How often participants buy groceries per month?

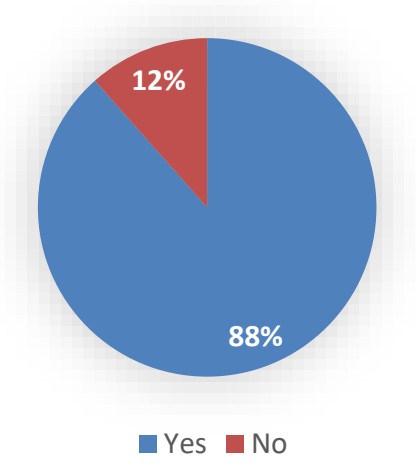

Fig. 10. Are participants currently ding their groceries shopping online?

Fig. 11 shows the most important factors to consumers when they are buying groceries online. These factors are including delivery time, price, quality of the products, and customer service. 133 participants consider the product's price as the most critical factor when buying groceries online, and they form $63.9 \%$ of the participants. Whereas 125 participants are considered the quality of the products as the most crucial factor, and they constitute $60.1 \%$ of the participants. On the other hand, 116 of the participants are considered the delivery time as the most vital factor when buying groceries online, and they form $55.8 \%$ of the participants. While $79 \%$ believe customer service the most critical factor, they comprise $38 \%$ of the participants.

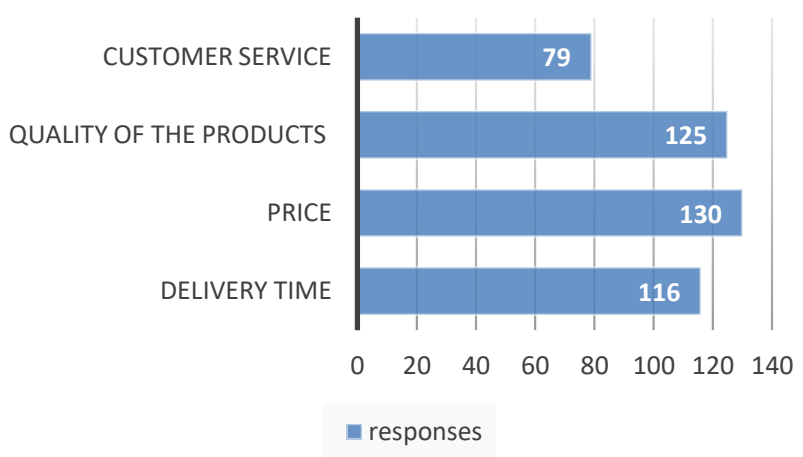

Fig. 11. The most important factors to consumers when they are buying groceries online.

\section{2) Logistics of electronic groceries}

Fig. 12 shows participants' opinions on whether if online grocery shopping and delivery services are convenient or not. Again, 184 participants have agreed that the online grocery shopping and delivery services are convenient, and they form $88.5 \%$ of the participants. On the other hand, 24 participants 
said "no," where they said that the online grocery shopping and delivery services are not convenient, and they form $11.5 \%$ of the participants.

Ammar Al Suleimani, the owner of Ayshay electronic grocery, said that online grocery shopping and delivery services are convenient. It saves time, effort, and money, especially for those consisting of 3 to 5 people. Both the husband and wife are employees, where usually, both will not have enough time to buy their grocery needs physically. So, they will prefer to buy their needs online.

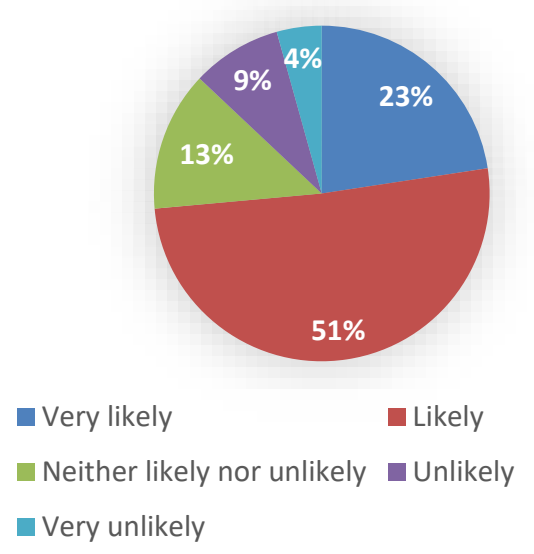

Fig. 12. Participants' opinion whether if online grocery shopping and delivery services are convenient.

Fig. 13 shows how far the participants will do their grocery shopping online even with a $5-10 \%$ increase in price with door-to-door delivery service availability. 31 of the participants said they would do their grocery shopping online even with a $5-10 \%$ increase in price with the availability of door-to-door delivery service. They form $14.9 \%$ of the participants. Besides, 107 participants said that they might do their grocery shopping online even with a $5-10 \%$ increase in price with door-to-door delivery service, and they form $51.4 \%$ of the participants. On the other hand, 70 participants said they would not do their grocery shopping online with the $5-10 \%$ increase in price, and they form $33.7 \%$ of the participants.

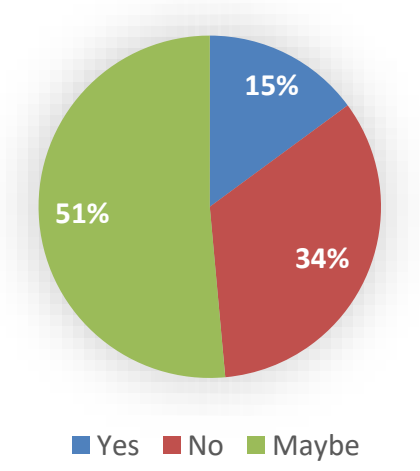

Fig. 13. How far the participants will do their grocery shopping online even with a $5-10 \%$ increase in price with door-to-door delivery service availability.

Fig. 14 shows how likely the participants would buy groceries online and have them delivered if there were an annual membership fee, but there are no delivery charges. 47 participants said they are "very likely" to buy groceries online and have them delivered if there were an annual membership fee without paying delivery charges. They form $22.6 \%$ of the participants. Besides, most participants said they "likely" would buy groceries online and have them delivered if there were an annual membership fee. Still, there are no delivery charges, where their number was 106 participants, and they form $51 \%$ of the participants. On the other hand, 28 of the participants have said that they "neither likely nor unlikely" would buy groceries online and have them delivered if there were an annual membership fee. Still, there are no delivery charges, and they form $13.5 \%$ of the participants.

On the other hand, 18 participants said they "unlikely" would buy groceries online and have them delivered if there were an annual membership fee without paying delivery charges. They form $13.5 \%$ of the participants, and only 9 of the participants have said that they "very unlikely" would buy groceries online and have them delivered if there were an annual membership fee. Still, there are no delivery charges, and they form $13.5 \%$ of the participants.

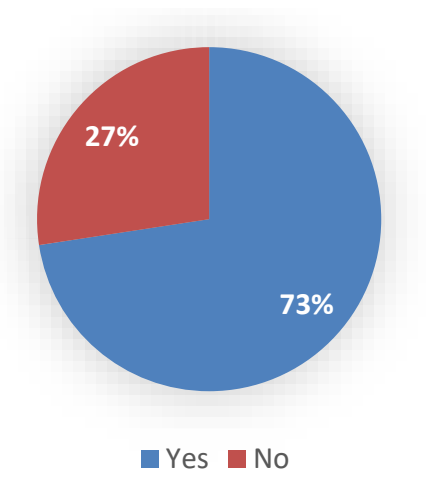

Fig. 14. How likely the participants would be to buy groceries online and have them delivered if there were an annual membership fee?

Fig. 15 shows how likely the participants would buy groceries online and have them delivered if Costs were slightly higher than regular grocery shop prices. Costs were a bit lower than everyday grocery shop prices; Costs were the same as the regular grocery shop prices, and There was a delivery service with a small fee per order.

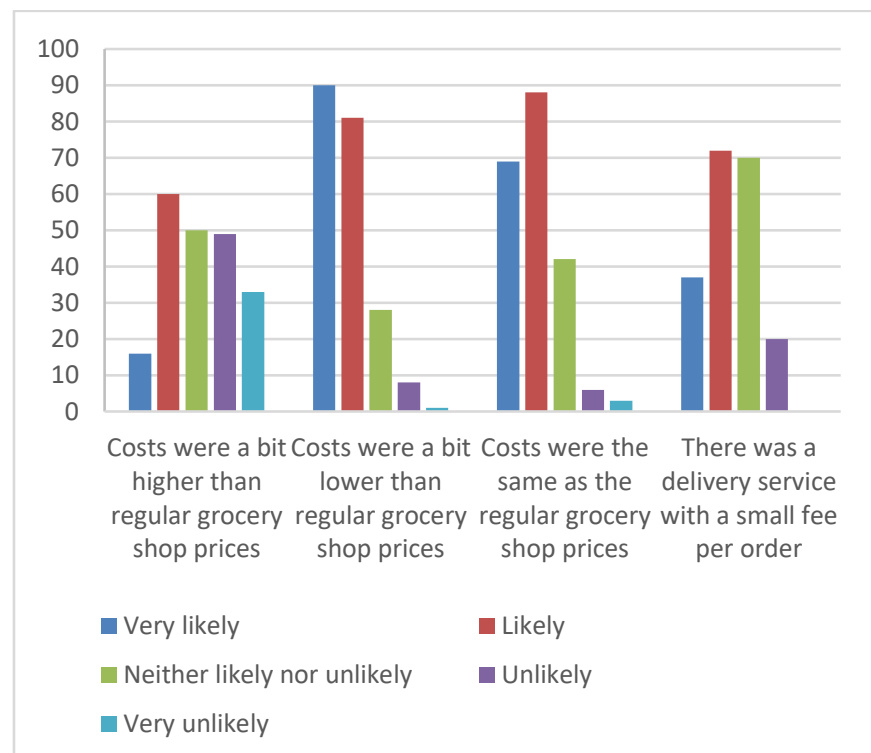

Fig. 15. How likely the participants would buy groceries online and have them delivered? 
If the costs were slightly higher than regular grocery shop prices, 16 participants said they would "very likely" buy groceries online and have them delivered. In contrast, 60 participants said they are "likely" to buy groceries online and have them delivered if the costs were a bit higher than regular grocery shop prices. Besides, 50 participants said they are "neither likely nor unlikely" to buy groceries online and have them delivered if the costs were a bit higher than regular grocery shop prices. On the other hand, 49 participants "unlikely" would buy groceries online and have them delivered if the costs were a bit higher than regular grocery shop prices. In comparison, 33 participants see that they are "doubtful" to buy groceries online and have them delivered if the costs were a bit higher than regular grocery shop prices.

If the costs were a bit lower than regular grocery shop prices, 90 participants are "very likely" to buy groceries online. In contrast, 81 participants are "likely" to buy groceries online if the costs were a bit lower than regular grocery shop prices. While 28 of the participants said they are "neither likely nor unlikely" would buy groceries online and have them delivered If the costs were a bit lower than regular grocery shop prices. On the other hand, 8 participants said they are "unlikely," and one participant only said that he is "doubtful" would buy groceries online and have them delivered if the costs were slightly lower than regular grocery shop prices.

If the costs were the same as the regular grocery shopping, 69 of the participants are "very likely" to buy groceries online. Unlikely, 88 of the participants are "likely" to buy groceries online. While 42 of the participants said that they are "neither likely nor unlikely" would buy groceries online and have them delivered, the costs were the same as the regular grocery shop prices. On the other hand, 6 participants said they are "unlikely," and 3 participants said they are "doubtful" would buy groceries online and have them delivered if the costs were the same as the regular grocery shop prices.

If there was a delivery service with a small fee per order, 37 participants are "very likely" to buy groceries online, and 72 of the participants are "likely" to buy groceries. While 70 participants said they are "neither likely nor unlikely" would buy groceries online and have them delivered If there was a delivery service with a small fee per order. On the other hand, 20 participants said they are "unlikely," and 9 participants said they are "doubtful" would buy groceries online and have them delivered If there was a delivery service with a small fee per order.

\section{3) Future of electronic groceries and its logistics movements in Oman}

In Oman, the future of electronic groceries logistics movements is still not clear due to the current situations of the COVID-19 and the lifestyle of Omani citizens. Saif Al Manji, a chief executive officer of the Geeb application, stated that the COVID-19 had affected the customer purchasing behaviour, where the demand increased on the electronic groceries and the number of online shoppers. In the covid-19 era, the lockdown forces many people to change their purchasing behaviour. Many people start using electronic shops and groceries to purchase their needs to adapt to the conditions of the current situation of the COVID19 pandemic. The logistic services that Geeb application provides are too flexible and attractive. Geeb app drivers' number is more than enough to cover the massive number of orders and deliver the customer needs on time. The application has an expandable fleet if the current situation forces them to increase the number of drivers.

Globally, the statistics show that the number of electronic grocery shoppers has increased due to the Covid-19 pandemic. However, in Oman, the reality proved to be different, where people still feel uncomfortable shopping for their grocery needs online, and many people do not have a credit card for it.

After the COVID-19 pandemic, people may change their purchasing behaviour online for the standard monthly or weekly grocery needs because it saves their time and effort and reachable from anywhere. However, the touch experience of shoppers is different and has a unique character to determine the purchase of the product, especially in Oman.

Similarly, Ali Al Ajili, a chief executive officer of Tawseel plus company, said that as logistics solutions providers, we had seen that customers' purchasing behaviour had been changed because of the COVID-19. We received a massive number of delivery orders compared with the period before the pandemic, with an average of 491 orders per month were grocery products orders. Thus, the increase of online grocery shoppers will increase the demand for logistics services. To avoid any delay due to the rise in rankings, we increase the numbers of drivers, where we are trying to be on time. As a logistic company, we encouraged people to shop their grocery needs online by being on time and reducing their expenses, efforts, and shopping time. Electronic groceries in Oman have a great future, especially with the increase of Oman's online shopping users due to the COVID-19, where this pandemic changed customers' purchasing behaviour. However, it will need a bit of time to reach $50 \%$ of Omani citizens who have changed their grocery shopping behaviour online.

\section{B. Discussion}

At this point, the researcher will analyze the results of the Survey and interviews obtained from participants and interviewees. Finding related to electronic groceries and purchasing behaviour vindicate that online grocery shopping is still early in Oman due to the lack of awareness of its positive side. Plus, the centralization of electronic groceries services in the main cities of Oman, where these e-groceries are covering mostly Muscat, Sohar, and Salalah.

\section{1) Purchasing behaviours}

The low number of electronic grocery users in Oman is caused due to the unavailability of offering attractive offers that may encourage society to use electronic shopping to buy their grocery needs. Also, the lack of customer awareness of the advantages of electronic shopping is another reason. The marketing of electronic groceries in Oman is not fair enough to reach many citizens and force them to use e-shopping. Furthermore, the negative reputation of electronic groceries in Oman is another reason there are many delays in delivering the products, according to Hanaa Al Mayahi (consumer). Furthermore, after-sales service is frail, where many customers can sometimes not return or exchange the items.

Besides, the limited options of items list are available in the local electronic groceries because of the uncomfortable 
online shopping for grocery needs. Sometimes, consumers may be forced to visit a local grocery and collect their needs physically since it is not available in online groceries. Also, electronic groceries services are available only in Oman's main cities, like Muscat, Sohar, and Salalah.

Generally, the online grocery shopping and delivery services are convenient because it saves time, effort, and money. Most participants have agreed that online grocery shopping and delivery services are convenient. Also, most consumers would likely buy groceries online and have them delivered if there were an annual membership fee. Still, there are no delivery charges and if the costs in the electronic groceries were a bit lower than regular grocery shop prices.

\section{2) Future of electronic groceries logistics in Oman}

The future of electronic grocery logistics movements in Oman is still not precise due to the current situations of the covid-19 and the lifestyle of Omani citizens. Generally, covid-19 had affected the customer purchasing behaviour. Thus, the demand increased for electronic groceries and the number of online shoppers due to the lockdown since it forced many people to change their purchasing behaviour to start using electronic shops and groceries to purchase their needs and adapt to the conditions of the current situation.

Globally, the statistics show that the number of electronic grocery shoppers has increased due to the COVID-19 pandemic. However, in Oman, the reality proved to be different, where people still feel uncomfortable shopping for their grocery needs online, and many people do not have a credit card for it. After the COVID-19 pandemic, people may change their purchasing behaviour online for the standard monthly or weekly grocery needs because it saves their time and effort and reachable from anywhere. However, shoppers' touch experience is different and has a unique character to determine the purchase of the product, especially in Oman.

Electronic groceries in Oman have a great future, especially with the increase of Oman's online shopping users due to the COVID-19, where this pandemic changed customers' purchasing behaviour. However, it will need a bit of time to reach $50 \%$ of Omani citizens who have changed their grocery shopping behaviour online, according to Ali Al Ajili.

\section{CONCLUSION AND RECOMMENDATION}

\section{A. Conclusion}

E-commerce of grocery products is related to using electronic networks as a distribution channel. Therefore, it targets individuals, described as a smooth and modern relation between business-to-consumer [1]. In this study, the researcher has analyzed customers purchasing behaviour and predict the future of logistics movements in online groceries in Oman. The study was conducted by distributing a survey to the grocery consumers in Oman, including citizens and residents, to evaluate their purchasing behaviour and satisfaction with online grocery shopping throughout the Sultanate of Oman. Meanwhile, interviews were conducted with two CEOs of local electronic groceries, one logistics services provider, and three consumers. The results illustrate a low number of electronic grocery users in Oman, which caused the unavailability of offering attractive offers that may encourage society to use electronic shopping to buy their grocery needs and the negative reputation of electronic groceries in Oman.

Furthermore, the lack of customer awareness of the advantages of electronic shopping is another reason. The marketing of electronic groceries in Oman is not fair enough to reach many citizens and force them to use e-shopping. The limited options of items list available at local electronic groceries are uncomfortable online shopping for grocery needs. Consumers are forced to visit their local grocery store to collect their needs because they are not available online. Electronic grocery services are available only in Oman's main cities, like Muscat, Sohar, and Salalah.

On the other hand, the future of electronic grocery logistics movements in Oman is still not precise due to the current situations of the COVID-19 and the lifestyle of Omani citizens. Nevertheless, the researcher predicts a high potential for electronic groceries to expand throughout the Sultanate of Oman due to the locals' increased demand for online shopping, especially during the COVID-19 pandemic. Finally, Omani consumers shifted their purchasing behaviour from traditional shopping that is time-consuming to shopping online, which is more convenient.

\section{B. Recommendations}

Electronic groceries in Oman have a more fantastic future, especially with the increase of Oman's online shopping users due to the COVID-19. The researcher offered the following recommendations based on the study that has been accomplished in this paper.

1. The Omani electronic groceries should improve their services effectively and efficiently to attract more customers and providing them with different commodities to satisfy their needs and wants.

2. E-grocery services should expand their markets throughout the Sultanate of Oman rather than offering their needs only to main cities such as Muscat, Sohar and Salalah.

3 . Facilitate using the grocery applications since not all people can understand all details in the currently available apps.

4. The Omani online groceries stores should provide an effective delivery service such as reverse logistics as an added value to their online services to attract their online customers

5. There should be enough skilled delivery personnel to meet online customers' demands and collaborate with thirdparty logistics companies to deliver orders on time.

6. E-grocery services providers should slow down their prices to attract and boost their online customers' loyalty and increase competitiveness in the online - groceries purchasing market.

7. There should be an application for small groceries to be registered in, which will help customers with several alternatives at the same spot.

\section{ACKNOWLEDGEMENT}

Without any doubt, the author thanks warmly everyone who helped in guiding and supporting the research with knowledge and advice to complete and finish the graduation project.

Special thanks to Dr Adela P Balasa's supervisor for her 
significant role in her constant, continuous supervision, guidance, and advice for completing the research.

Special gratitude and thanks also to the co-supervisor, $\mathrm{Mr}$ Zouhaier Slimi, for his guidance and constant supervision towards this project.

Also, the researcher would like to thank Mr Saif Al Manji, a CEO of the Geeb application; Mr Ammar Al Suleimani, a CEO of Ayshay application; Mr Ali Al Ajili, CEO of Tawseel plus company, Sami Awladwadair, Hanaa Al Mayahi, and Noor Akbar for their cooperation on conducting the research interviews, and all participants in the survey.

\section{REFERENCES}

[1] M. Khosrow-Pour, Encyclopedia of e-commerce, e-government, and mobile commerce, illustrated edition ed., Idea Group Reference, 2006.

[2] A. Raijas and V. K. Tuunainen, "Critical factors in electronic grocery shopping," The International Review of Retail, Distribution and Consumer Research, vol. 11, no. 3, pp. 255-265, 2011.

[3] OECD, "E-commerce in the time of COVID-19," OECD Policy Responses to Coronavirus (COVID-19), 07 October 2020.

[4] K. Verweire and L. V. D. Berghe, Integrated Performance Management, London: SAGE Publications, 2004.

[5] B. Morgan, "50 Statistics Showing The Lasting Impact Of COVID-19 On Consumers," 19 October 2020.

[6] Orpic, "Oman $\$ 1.5$ billion Sohar Refinery expansion near EPC stage," $\begin{array}{llll}\text { Orpic, } & 14 & 09 & 2012 .\end{array}$ https://2b1stconsulting.com/oman-1-5-billion-sohar-refineryexpansion-at-epc-stage/. [Accessed 2201 2021].

[7] L.-J. Ho, " The influences of social commerce characteristics on satisfaction, reliability and repurchase intention.," pp. 16-25, 2013.

[8] Zhang, Y. Fang and H. Chen, "Repurchase intention in B2C ecommerce - A relationship quality perspective," pp. 192-200, 2011.

[9] Euromonitor, "COVID-19 to Accelerate Online Grocery Shopping Beyond 2021," 2020. [Online]. Available: https://blog.euromonitor.com/covid-19-to-accelerate-online-groceryshopping-beyond-2021/. [Accessed 2602 2021].

[10] Z. Anesbury, M. Nenycz, J. Dawes and R. Kennedy, "How do shoppers behave online? An observational study of online grocery shopping," Consumer Behaviour, vol. 15, no. 3, pp. 261-270, 2015.

[11] OECD, "Food Supply Chains and COVID-19: Impacts and Policy Lessons," $2020 . \quad$ [Online]. Available: http://www.oecd.org/coronavirus/policy-responses/food-supplychains-and-covid-19-impacts-and-policy-lessons-71b57aea/. [Accessed 24 February 2021].

[12] OECD, "Connecting Businesses and Consumers During COVID-19: Trade in Parcels," OECD, Globally, 2020.

[13] OECD, "COVID-19 and the retail sector: impact and policy responses," $2020 . \quad$ [Online]. http://www.oecd.org/coronavirus/policy-responses/covid-19-and-theretail-sector-impact-and-policy-responses-371d7599/.. [Accessed 24 February 2021].

[14] N. N. Long and B. H. Khoi, "An Empirical Study about the Intention to Hoard Food during COVID-19 Pandemic," vol. 16, no. 7, 2020.

[15] A. Bjørgen, K. Y. Bjerkan and O. A. Hjelkrem, "E-groceries: Sustainable last-mile distribution in city planning," Research in Transportation Economics, p. 9, 2019.

[16] T. Esper, T. D. Jensen , F. Turnipseed and S. Burton, "THE LAST MILE: AN EXAMINATION OF EFFECTS OF ONLINE RETAIL DELIVERY STRATEGIES ON CONSUMERS," Journal of Business logistics, vol. 24, no. 2, pp. 177-203, 2003.

[17] M. Henriksson, J. Karlsson, S. Rogerson and J. Berg, "The impact of increased e-commerce for passenger and freight transport in an increasing e-commerce society," Buying food online?, p. 71, 2018.

[18] R. David, "What Attracts Customers to Online Stores, and What Keeps Them Coming Back?," Journal of the Academy of Marketing Science, vol. 30, no. 4, p. 468, 2002.

[19] A. Banerjee and F. Siemens, "Logistics of E-Groceries," Innovations and Strategies for Logistics and Supply Chains, vol. 20, pp. 91-116,
2015.

[20] A. Banerjee and F. Siemens, "Logistics of E-Groceries," : Innovations and Strategies for Logistics and Supply Chains, vol. 20, pp. 91-116, 2015.

[21] P. Schnedlitz, E. Lienbacher, B. Waldegg-Lindl and M. WaldeggLindl, "Last Mile: Die letzten - und teuersten - Meter zum Kunden im B2C ECommerce," pp. 249-273, 2013.

[22] N. A. Agatz, A. Campbell and M. Savelsbergh, "Time Slot Management in Attended Home Delivery," Transportation Science, vol. 45, no. 3, p. 435-449, 2011.

[23] J. L. Anderson, L. D. Jolly and A. E. Fairhurst, "Customer relationship management in retailing," A content analysis of retail trade journals, vol. 14, no. 6, p. 394-399, 2007.

[24] D. Grewal, A. L. Roggeveen and J. Nordfalt, "The Future of Retailing," vol. 93, no. 1, pp. 1-6, 2017.

[25] I. Cil, D. Ay and Y. S. Turkan, "Data driven decision support to supermarket layout," pp. 465-470, 2009.

[26] K. v. Ittersum, B. Wansink and J. M. Pennings, "Smart Shopping Carts," How Real-Time Feedback Influences Spending, vol. 77, no. 6, p. 21-36, 2013.

[27] S. Yang, Y. Song and S. Tong, "Sustainable Retailing in the Fashion Industry," A Systematic Literature Review, vol. 9, no. 7, p. 1266, 2017.

[28] Shoppu, "Malaysian online shopping insights," 2016. [Online]. Available: https://www.ecommercemilo.com/2016/03/malaysianonline-shopping-insights-2016. [Accessed 11 November 2020].

[29] W. Wang, Y. Liu and Y. Wei, "Research on management strategies of reverse logistics in e-commerce environments," Journal of System and Management Sciences, vol. 3, no. 2, pp. 45-50, 2013.

[30] S. Nasir and B. Kurtuluş, "Technology Is Transforming Shopping Behavior," In-Store Mobile Technology Usage, pp. 1508-1529, 2017.

[31] N. Ramli, "THE ART OF CUSTOMER SERVICE TECHNIQUES," 2015. [Online]. Available: https://prezi.com/g5mqeth8ldih/the-art-ofcustomer-service-techniques/. [Accessed 05 December 2020].

[32] S. K. Panigrahi, F. W. Kar, T. A. Fen, L. K. Hoe and M. Wong, "A Strategic Initiative for Successful Reverse Logistics Management in Retail Industry," vol. 19, no. 1, pp. 1-25, 2018.

[33] B. K. Karel, M. T. Frohlich, G. Hult and Tomas M, Extending the supply chain: how cutting-edge companies bridge the critical last mile into customers' homes, 1st ed., New York: American Management Association, 2005.

[34] R. Frankel, T. J. Goldsby and J. M. Whipple, "Grocery industry collaboration in the wake of ECR," International Journal of Logistics Management, vol. 13, no. 1, p. 57-72, 2002.

[35] J. Creswell, Research design (Qualitative, Quantitative, and Mixed Methods Approaches), Los Angeles: SAGE, 2014.

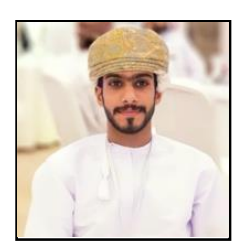

Abdul Rahman Rashid Saleh Al-Hawari

Sultanate of Oman, Suhar, July 24, 1998

The author B.A in Logistics and Transport Management/ International Maritime College Oman, Suhar, Sultanate of Oman.

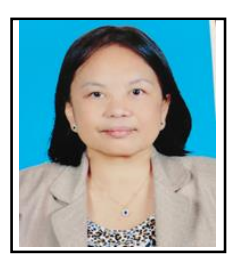

Adela P. Balasa is Doctor of Public Administration (DPA), The University of Manila, Manila, Philippines, October 2002. She is presently working as an Associate Professor of Economics at Intranational Maritime College Oman, Sohar, Sultanate of Oman, from February 2009 up to now.

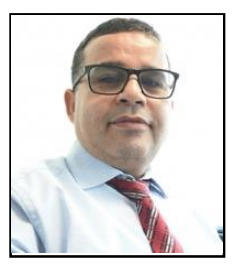

Mr Slimi, PhD student at Deusto University/Spain. $\mathrm{MA}$ in the Arts o learning and teaching Roehampton/UK. B.A in English language and Literature Sousse/Tunisia. Member of European Journal of Educational Science, EJES reviewal team. 